\title{
Impaired neurodevelopmental pathways in autism spectrum disorder: a review of signaling mechanisms and crosstalk
}

\author{
Santosh Kumar, Kurt Reynolds, Yu Ji, Ran Gu, Sunil Rai and Chengji J. Zhou* (iD
}

\begin{abstract}
Background: The development of an autistic brain is a highly complex process as evident from the involvement of various genetic and non-genetic factors in the etiology of the autism spectrum disorder (ASD). Despite being a multifactorial neurodevelopmental disorder, autistic patients display a few key characteristics, such as the impaired social interactions and elevated repetitive behaviors, suggesting the perturbation of specific neuronal circuits resulted from abnormal signaling pathways during brain development in ASD. A comprehensive review for autistic signaling mechanisms and interactions may provide a better understanding of ASD etiology and treatment.

Main body: Recent studies on genetic models and ASD patients with several different mutated genes revealed the dysregulation of several key signaling pathways, such as WNT, BMP, SHH, and retinoic acid (RA) signaling. Although no direct evidence of dysfunctional FGF or TGF- $\beta$ signaling in ASD has been reported so far, a few examples of indirect evidence can be found. This review article summarizes how various genetic and non-genetic factors which have been reported contributing to ASD interact with WNT, BMP/TGF- $\beta$, SHH, FGF, and RA signaling pathways. The autism-associated gene ubiquitin-protein ligase E3A (UBE3A) has been reported to influence WNT, BMP, and RA signaling pathways, suggesting crosstalk between various signaling pathways during autistic brain development. Finally, the article comments on what further studies could be performed to gain deeper insights into the understanding of perturbed signaling pathways in the etiology of ASD.

Conclusion: The understanding of mechanisms behind various signaling pathways in the etiology of ASD may help to facilitate the identification of potential therapeutic targets and design of new treatment methods.
\end{abstract}

Keywords: WNT, BMP/TGF- $\beta$, SHH, FGF, Retinoic acid (RA), Signaling crosstalk, Autism spectrum disorder, Neurodevelopmental disorders

\section{Background}

Autism spectrum disorder (ASD) is a multifactorial neurodevelopmental disorder characterized by impaired social interactions and elevated repetitive behaviors, in which various circuits in the sensory, prefrontal, hippocampal, cerebellar, striatal, and other midbrain regions are perturbed $[1,2]$. Compared to de novo non-coding variations, the de novo coding variants have a strong association with ASD as shown by the whole-genome sequence association (WGSA) studies in 519 ASD families [3]. Kosmicki et al.

\footnotetext{
*Correspondence: samkumar@ucdavis.edu; cjzhou@ucdavis.edu Department of Biochemistry and Molecular Medicine, Institute for Pediatric Regenerative Medicine of Shriners Hospitals for Children, University of California at Davis School of Medicine, 2425 Stockton Blvd, Sacramento, CA 95817, USA
}

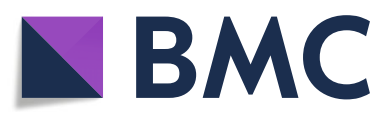

(c) The Author(s). 2019 Open Access This article is distributed under the terms of the Creative Commons Attribution 4.0 International License (http://creativecommons.org/licenses/by/4.0/), which permits unrestricted use, distribution, and reproduction in any medium, provided you give appropriate credit to the original author(s) and the source, provide a link to the Creative Commons license, and indicate if changes were made. The Creative Commons Public Domain Dedication waiver (http://creativecommons.org/publicdomain/zero/1.0/) applies to the data made available in this article, unless otherwise stated. ADNP, ANK2, DSCAM, SCN2A, ASH1L, CHD2, KDM5B, and $P O G Z$ genes with $\geq 3$ class 1 de novo protein-truncating variants (PTVs) in individuals with ASD [4]. ANK2, CHD8, CUL3, DYRK1A, GRIN2B, KATNAL2, POGZ, SCN2A, and TBR1 genes are identified as high-confidence ASD risk genes, of which CHD8 is strongly associated with ASD because of the largest number of de novo loss-of-function (LOF) mutations observed in patients [5, 6]. Various gene mutations reported in ASD patients are either core components of the WNT signaling pathway or their modulators [7-9]. More recently, a few reports support the idea of modulation of bone morphogenetic protein (BMP) signaling as a contributing factor in ASD model organisms and humans. For instance, 
Neuroligins $(N L G N)$, fragile $\mathrm{X}$ mental retardation 1 (FMR1), ubiquitin-protein ligase E3A (UBE3A), and $D L X$, which modulate BMP signaling, have been found to be associated with ASD [10-13]. Dysregulation of sonic hedgehog $(\mathrm{SHH})[14,15]$, fibroblast growth factor (FGF) [16], transforming growth factor $\beta$ (TGF- $\beta$ ) $[17,18]$, and retinoic acid (RA) [19] signaling pathways have also been implicated in the pathogenesis of ASD. Valproic acid (VPA), used in the treatment of epilepsy and bipolar disorder, may affect the $\mathrm{WNT} / \beta$-catenin signaling pathway. However, its prenatal exposure in rats also causes susceptibility to autism [20]. Due to the scarcity of information on the mechanisms underlying the etiologies of ASD, the success of therapeutic strategies is greatly limited.

\section{Altered WNT signaling in ASD}

WNT signaling is fundamental for neurodevelopmental and post-neurodevelopmental processes, such as CNS regionalization, neural progenitor differentiation, neuronal migration, axon guidance, dendrite development, synaptogenesis, adult neurogenesis, and neural plasticity [21-30], and therefore, any perturbation in WNT signaling may trigger the advent of disorders related to the structures and functions of the CNS [9,31]. Studies in genetically modified animal models and human induced pluripotent stem cell (hiPSC) models, along with large-scale human genomic studies in several neurodevelopmental disorders over the last few decades, have revealed the importance of spatiotemporal regulation of WNT signaling throughout the lifespan of an animal [9]. Moreover, dysregulation of WNT signaling has been reported in several psychiatric disorders, including ASD, bipolar disorder, and schizophrenia, as well as in case of intellectual disability [8, 9, 31-34]. Although several genetic and epigenetic factors have been linked with the etiologies of neurodevelopmental disorders, they often seem to affect a few common processes, such as chromatin remodeling, WNT signaling, and synaptic function [32, 35, 36]. Despite the heterogeneity in WNT signaling, it is broadly classified into "canonical" ( $\beta$-catenin-dependent) and "non-canonical" ( $\beta$-catenin-independent) pathways [37, 38]. Both canonical and non-canonical WNT signaling pathways play crucial roles in neural development and related neurodevelopmental disorders.

\section{Genetic etiologies}

Several genetic loci/mutations linked to and/or reported in ASD patients are either core components of canonical WNT signaling, such as $\beta$-catenin $(C T N N B 1)[8,9,36,39]$ and adenomatous polyposis coli $(A P C)$ [1], or non-canonical WNT signaling, such as PRICKLE2 [40], suggesting crucial roles of both canonical and non-canonical WNT signaling pathways in the etiologies of ASD (Table 1 and Fig. 1).

\section{Core components of canonical WNT signaling}

WNTs Among 19 WNT ligands, mutations in WNT1, WNT2, WNT3, and WNT9B have been linked with ASD. A rare WNT1 missense variant found in ASD patients has a higher capability than the wild-type WNT1 to activate $\mathrm{WNT} / \beta$-catenin signaling [34]. Rare variants in WNT2, WNT3, and WNT9B have also been found in ASD patients [41-44]. Notably, WNT3 expression is elevated in the prefrontal cortex of ASD patients [45], suggesting overactivation of WNT signaling leads to ASD pathogenesis. In animal models, Wnt1 is required for midbrain and cerebellar development [46-48]. Wnt2 has been shown to be sufficient for cortical dendrite growth and dendritic spine formation, and its expression is regulated by a brain-derived neurotrophic factor (BDNF) [49], while altered dendritic spines result in neurodevelopmental and neurodegenerative disorders [49]. Wnt3 is essential for gastrulation and regulates hippocampal neurogenesis [50, 51]. Loss-of-function of T-brain-1 (Tbr1), a T-box transcription factor and one of the high-confidence ASD risk genes, in cortical layer 6 neurons ( $T b r 1^{\text {layer6 }}$ mutant) during late mouse gestation has been reported to cause a decrease in inhibitory synaptic density and excitatory synapse numbers [52]. It is important to note that the restoration of $W n t 7 b$ expression rescues the synaptic deficit in $\mathrm{Tbr} 1^{\text {layer6 }}$ mutant neurons [52]. Wnt9b promotes lip/palate formation and fusion $[53,54]$, while its role in neurodevelopment remains unclear. In addition to the other WNT ligands, there are various types of WNT receptors, including FZD1 to FZD10, LRP5/6, RYK, and ROR1/2 [30, 55], whose roles in ASD etiology remain elusive.

APC The tumor suppressor APC is a key component of the $\beta$-catenin-destruction complex [56]. Human APC inactivating gene mutations have been linked to ASD $[57,58]$. Compared with wild-type littermates, conditional knockout (cKO) Apc mice exhibit learning and memory impairment and autistic-like behaviors [1]. $\beta$-catenin and canonical WNT target gene expressions (Dkk1,Sp5, Neurog1, Syn2) are increased in Apc-cKO forebrain neurons [1]. Moreover, the lysates from the hippocampal, cortical, and striatal regions of $A p c-\mathrm{cKO}$ mice showed higher $\beta$-catenin levels compared to those of control mice [1]. These results also indicate that overactivation of $\mathrm{WNT} / \beta$-catenin signaling may be a cause of ASD.

CTNNB1 ( $\beta$-catenin) $\beta$-Catenin is a key intracellular molecule in the canonical WNT signaling pathway and 


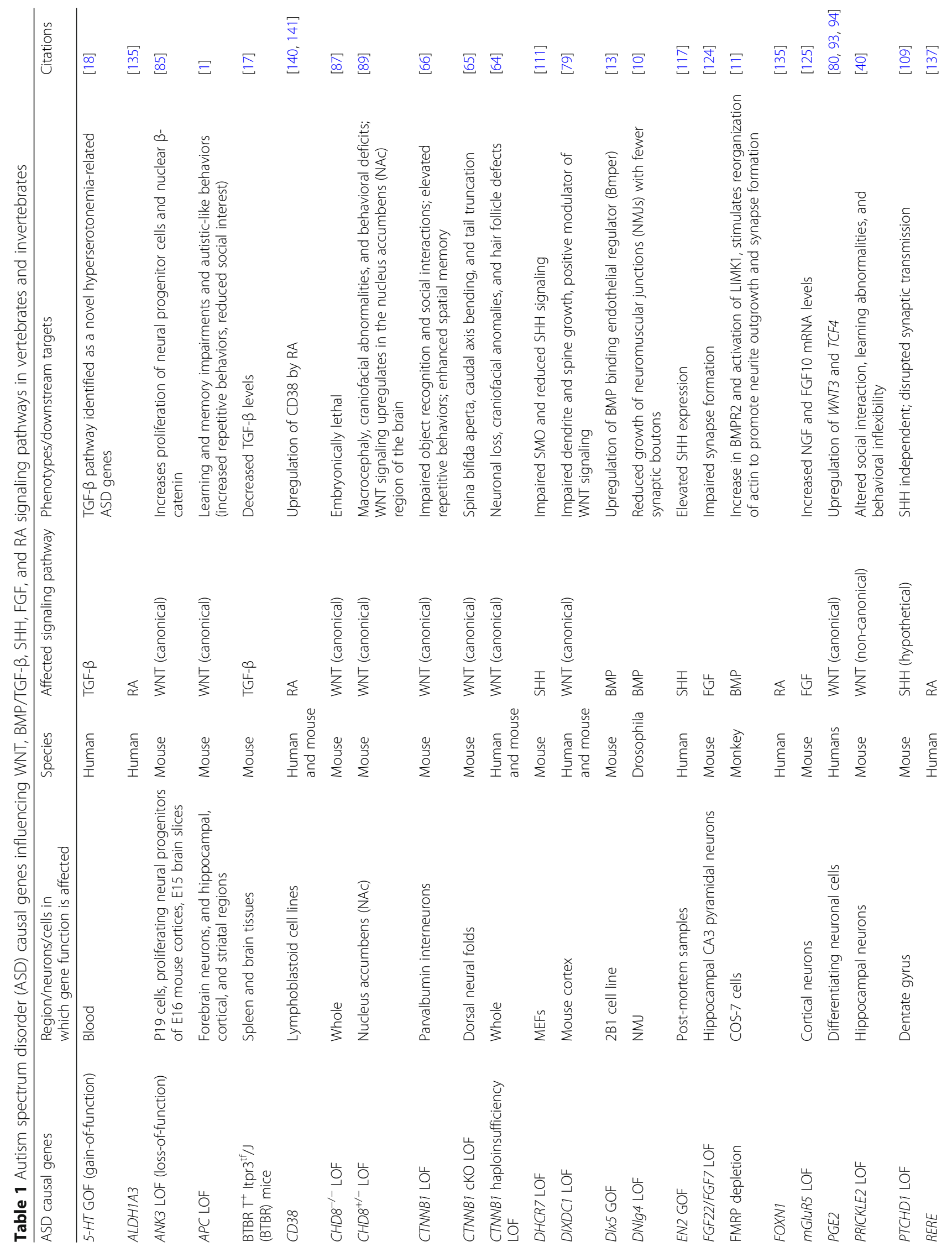




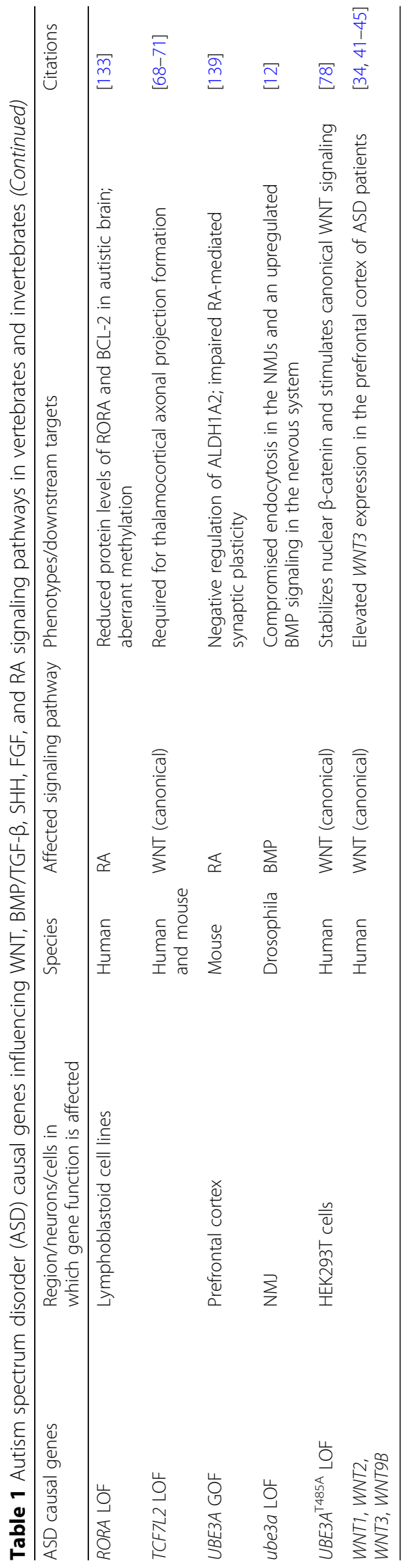




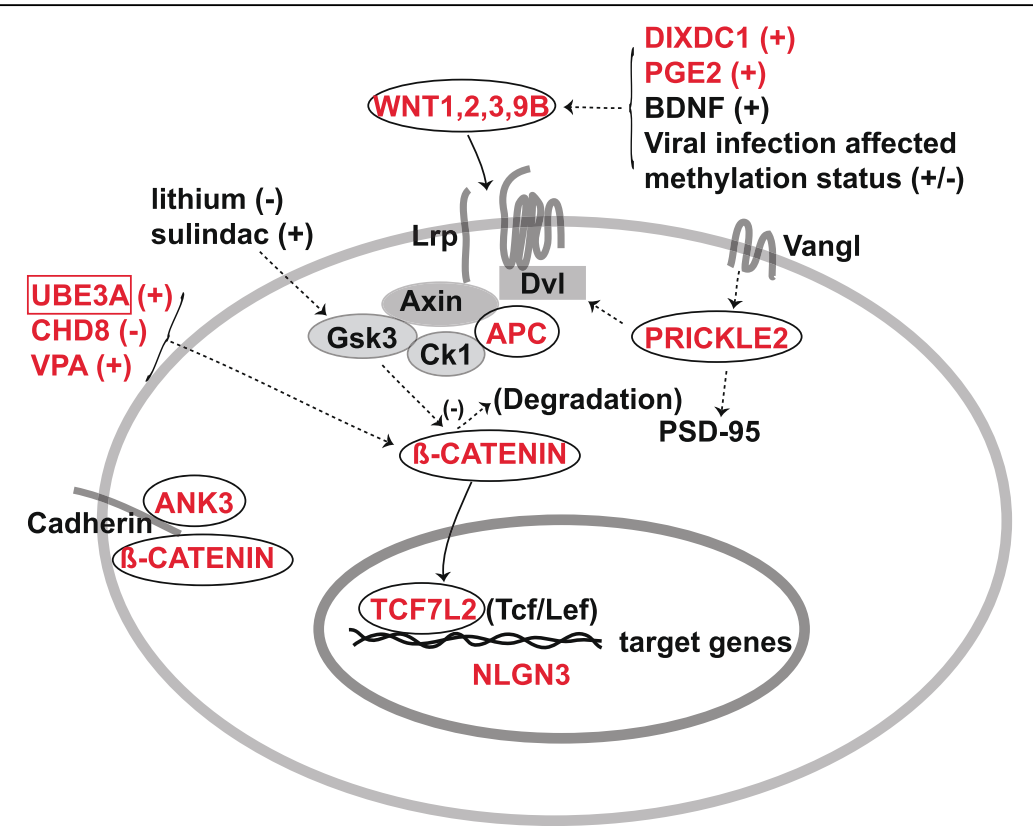

Fig. 1 Possible interactions between ASD causal genes and WNT signaling. Most molecules (red) encoded by the ASD-associated genes are either core components of WNT signaling pathways, such as WNTS, APC, $\beta$-catenin, TCF7L2, and PRICKLE2, or their modulators, such as DIXDC1, PGE2, UBE3A, and CHD8. ANK3 interacts with $\beta$-catenin at the plasma membrane. Note: plus sign indicates upregulation; minus sign indicates downregulation

plays significant roles in development and disease [59, 60]. De novo CTNNB1 mutations have been reported in individuals with ASD, intellectual disability, microcephaly, motor delay, and speech impairment [36, 39, 61-63]. CTNNB1 haploinsufficiency has been found to cause neuronal loss, craniofacial anomalies, and hair follicle defects in both humans and mice [64]. Conditional ablation of $\beta$-catenin in the dorsal neural folds of mouse embryos represses the expression of $P a x 3$ and $C d x 2$ at the dorsal posterior neuropore and leads to a decreased expression of the $\mathrm{WNT} / \beta$-catenin signaling target genes $T, T b \times 6$, and $F g f 8$ at the tail bud, resulting in spina bifida aperta, caudal axis bending, and tail truncation [65]. Conditional ablation of $\beta$-catenin in parvalbumin interneurons in mice leads to impaired object recognition and social interactions, as well as elevated repetitive behaviors, which are core symptoms of ASD patients, and surprisingly, they showed enhanced spatial memory [66]. These mice have reduced c-Fos activity in the cortex, which is unaffected in the dentate gyrus and the amygdala, suggesting a cell type-specific role of $\beta$-catenin in the regulation of cognitive and autistic-like behaviors [66].

TCF7L2 (TCF4) TCF7L2 is one of the TCF/LEF1 transcription factors in the canonical $\mathrm{WNT} / \beta$-catenin signaling pathway and is associated with type II diabetes in humans [67]. De novo loss-of-function variants of TCF7L2 have been found in ASD patients $[68,69]$. In mice, Tcf7l2 is required for the formation of thalamocortical axonal projections, as is the key Wnt co-receptor Lrp6 [70, 71], suggesting that abnormal thalamocortical axonal inputs may contribute to ASD. It remains unclear if other members of the TCF/Lef1 transcription factors are associated with ASD.

\section{Core components of non-canonical WNT signaling}

PRICKLE2 PRICKLE2 variants (p.E8Q and p.V153I) have been reported in ASD patients [40]. PRICKLE2's role in ASD is further supported by the finding of a $3 p$ interstitial deletion including PRICKLE2 in identical twins with ASD [72]. Prickle2-deficient mice display ASD-like phenotypes, such as altered social interaction, learning abnormalities, and behavioral inflexibility [40]. PRICKLE2 is known to interact with post-synaptic density protein-95 (PSD-95), and this relationship is enhanced by Vangl2, a key component in the non-canonical WNT/PCP (planar cell polarity) pathway [73]. Reduced dendrite branching, synapse number, and PSD size have been observed in hippocampal neurons of Prickle2-deficient mice [40]. An in vitro study shows that Prickle1 and Prickle2 promote neurite outgrowth via a Dvl-dependent mechanism [74]. Future works need to address the involvement of other PCP genes and the signaling interaction between the PCP and $\mathrm{WNT} / \beta$-catenin signaling pathways in ASD etiology. 
Modulators and effectors of WNT signaling in ASD etiology Several ASD-associated genes are direct or indirect modulators of WNT signaling, such as ankyrin-G (ANK3) [75-77], chromodomain helicase DNA-binding protein 8 (CHD8) [5, 6], HECT domain E3 ubiquitin ligase $(U B E 3 A)$ [78], DIX domain-containing 1 (DIXDC1) [79], and Prostaglandin E2 (PGE2) [80] (Table 1 and Fig. 1). Intriguingly, a recent study suggests that the ASD-associated gene Neuroligin $3(\mathrm{Nlgn} 3)$ is a direct downstream target of $\mathrm{WNT} / \beta$-catenin signaling during synaptogenesis [81] (Fig. 1).

ANK3 Whole-genome and whole-exome sequencing studies in ASD patients have identified mutations in ANK3 gene [75-77]. Ankyrin-G, a scaffolding protein encoded by $A N K 3$ gene, localizes to the axon initial segment (AIS) and the nodes of Ranvier, where it has roles in the assembly and maintenance of the AIS and neuronal polarity $[82,83]$. Ankyrin-G facilitates cell-cell contact by binding to E-cadherin at a conserved site distinct from that of $\beta$-catenin and localizes it to the cell adhesion site along with $\beta$-2-spectrin in early embryos and cultured epithelial cells [84]. Ankyrin-G is enriched at the ventricular zone of the embryonic brain, where it regulates the proliferation of neural progenitor cells [85]. Ankyrin-G LOF increases the proliferation of neural progenitor cells and nuclear $\beta$-catenin, probably by disruption of the $\beta$-catenin/cadherin interaction [85].

CHD8 CHD8, an ATP-dependent chromatin remodeler, interacts with $\beta$-catenin and negatively regulates the expression of $\beta$-catenin-targeted genes [86]. CHD8 binding to p53 leads to the formation of a trimeric complex with histone $\mathrm{H} 1$ on chromatin, which suppresses p53-dependent transactivation and apoptosis during early embryogenesis [87]. CHD8 is also required for the expression of E2 adenovirus promoter-binding factor target genes during the G1/S transition of the cell cycle [88]. Chd8 gene knockout $\left(C h d 8^{-/-}\right)$in mice is embryonic lethal [87], whereas its heterozygous LOF mutations $\left(C h d 8^{+-}\right)$result in mice with macrocephaly, craniofacial abnormalities, and behavioral deficits [89]. Its knockdown in SK-N-SH human neural progenitor cells alters the expression of genes involved in neuronal development [90]. WNT signaling is upregulated in the nucleus accumbens (NAc) region of the brain of $C h d 8^{+/-}$mice, highlighting the critical role CHD8 plays in the regulation of WNT signaling in the NAc [89].

UBE3A Dysfunction of $U B E 3 A$ is linked to autism, Angelman syndrome, and cancer [78]. $U B E 3 A^{\mathrm{T} 485 \mathrm{~A}}$, a de novo autism-linked $U B E 3 A$ mutant that disrupts phosphorylative control of UBE3A activity, ubiquitinates multiple proteasome subunits, reduces proteasome subunit abundance and activity, stabilizes nuclear $\beta$-catenin, and stimulates canonical WNT signaling more effectively than the wild-type UBE3A [78].

DIXDC1 Rare missense variants in DIXDC1 were identified in ASD patients [79]. These variants prevent phosphorylation of DIXDC1 isoform 1, causing impairment to dendrite and spine growth [79]. DIXDC1 is a positive modulator for WNT signaling and regulates excitatory neuron dendrite development and synapse function in the mouse cortex [79]. MARK1, which is also linked to ASD, phosphorylates DIXDC1 to regulate dendrite and spine development through modulation of the cytoskeletal network in an isoform-specific manner [79]. Dixdc1-deficient mice exhibit behavioral disorders, including reduced social interaction, which can be alleviated through pharmacological inhibition of Gsk3 to upregulate WNT/ $\beta$-catenin signaling $[91,92]$. These studies suggest a potential approach to ASD treatment through manipulation of WNT/ $\beta$-catenin signaling activities.

PGE2 PGE2, an endogenous lipid molecule, has been linked to ASD and alters the expression of downstream WNT-regulated genes previously associated with neurodevelopmental disorders [80]. The link between prostaglandin and autism came from the report of Möbius sequence with autism and positive history of misoprostol use during pregnancy [93]. The prostaglandin analog misoprostol is used as an abortifacient as well as for the prevention of gastric ulcers. Among seven children with ASD, four (57.1\%) had prenatal exposure to misoprostol [93, 94]. In undifferentiated stem cells, PGE2 downregulates PTGS2 expression and upregulates $M M P 9$ and $C C N D 1$ expression, whereas in differentiating neuronal cells, PGE2 causes upregulation of WNT3, TCF4, and CCND1 [80].

NLGN3 Mutations in neuroligins NLGN3 and NLGN4 have been reported in autistic patients [95]. These type I transmembrane proteins are neural cell adhesion molecules and are required for the formation and development of synapses [10]. Chromatin immunoprecipitation and promoter luciferase assays demonstrate that WNT/ $\beta$-catenin signaling directly regulates Nlgn3 expression [81]. It will be important to address whether $\mathrm{WNT} / \beta$-catenin signaling regulates other ASD-associated genes.

\section{Altered TGF- $\beta$ /BMP signaling in ASD}

The TGF- $\beta$ /activin and the bone morphogenetic protein (BMP)/growth and differentiation factor (GDF) are the two subgroups of TGF- $\beta$ superfamily [96]. BMPs constitute the largest subdivision of the TGF- $\beta$ superfamily [97] and are critical in the development of the nervous system [98]. Their signaling has been shown to be dysregulated in ASD. BMPs regulate the expression of 
various genes by the canonical pathway (Smad-dependent) and non-canonical pathways (such as MAPK cascade) [99]. In the canonical pathway, the binding of BMPs to type I or type II serine/threonine kinase receptors forms a heterotetrameric complex. This leads to the transphosphorylation of the type I receptor by the type II receptor. The type I receptor then phosphorylates the R-Smads (Smad1/5/8). The phosphorylated Smad1/5/8 along with the co-Smad $(\operatorname{Smad} 4)$ translocate to the nucleus and regulate gene expression. There are various factors such as plasma membrane co-receptors and extracellular and intracellular factors known to modulate BMP signaling [99]. BTBR $\mathrm{T}^{+}$Itpr $3^{\text {tf }} / \mathrm{J}$ (BTBR) mice are widely used in the study of ASD [17]. It has been reported that TGF- $\beta$ levels are reduced in BTBR mice in comparison with B6 mice [17] (Table 1). Significant changes in the expression of TGF- $\beta$ have been found in the spleen and brain tissues of BTBR mice compared to those in adenosine A2A receptor (A2AR) agonist CGS 21680 (CGS)-treated mice [17]. ASD has been linked with higher levels of serotonin (5-hydroxytryptamine or 5-HT) in the blood [18] (Table 1). In a network-based gene set enrichment analysis (NGSEA), components of the TGF- $\beta$ pathway have been identified as novel hyperserotonemia-related ASD genes, based on LOF and missense de novo variants (DNVs) [18].

NLGN4 Drosophila neuroligin 4 (DNlg4) LOF results in reduced growth of neuromuscular junctions (NMJs), with fewer synaptic boutons due to the reduction in the bone morphogenetic protein (BMP) type I receptor thickvein $(T k v)$ [10], suggesting important roles of BMP signaling in normal and autistic brains.

FMR1 Fragile X syndrome (FXS) is the most common heritable form of intellectual disability and ASD, which is caused due to the silencing of FMR1 [11]. FMR1 protein (FMRP) depletion results in an increase in the bone morphogenetic protein type II receptor (BMPR2) and activation of a non-canonical BMP signaling component LIM domain kinase 1 (LIMK1), which stimulates reorganization of actin to promote neurite outgrowth and synapse formation [11]. Increased BMPR 2 and $L I M K 1$ activity has been reported in the prefrontal cortex of FXS patients compared with that of healthy subjects [11].

UBE3A The inhibition of BMP signaling by Ube3a has been reported to play a role in the regulation of synapse growth and endocytosis [12]. A direct substrate of ube3a, the BMP receptor Tkv, is degraded through the ubiquitin-proteasome pathway [12]. Drosophila ube3a has been known to regulate the NMJ development in the presynaptic neurons through the BMP signaling pathway [12]. Drosophila ube3a mutants have been shown viable and fertile. However, they display compromised endocytosis in the NMJs and upregulated BMP signaling in the nervous system due to an increase in $T k v$ [12].

DLX The $D L X$ genes encoding homeodomain transcription factors have been associated with ASD [100-102]. These genes control craniofacial patterning and differentiation and survival of forebrain inhibitory neurons [100]. The BMP-binding endothelial regulator (Bmper) has been found upregulated in a cell line overexpressing $D l x 5$ [13], suggesting dysregulated $D L X$ function in ASD patients may lead to altered BMP signaling.

\section{Altered SHH signaling in ASD}

$\mathrm{SHH}$ plays a crucial role in the organization of the vertebrate brain [103]. SHH has a wide range of roles in developing as well as the adult brain and drives proliferation, specification, and axonal targeting within the forebrain, hindbrain, and spinal cord [104]. Although the role of neural primary cilia in embryonic CNS patterning is well studied, their role in adult CNS plasticity has recently emerged [105]. SHH signaling at the primary cilium has been described [106] and is summarized in Fig. 2. In the absence of SHH activity, PTCH represses SMO. This leads to the phosphorylation of GLI proteins, and their subsequent proteolytic truncation into repressor forms that inhibit transcriptional activity. However, the binding of $\mathrm{SHH}$ to PTCH causes its internalization followed by degradation which in turn leads to SMO accumulation and phosphorylation. In this case, GLI is transported to the cytosol and enters the nucleus in its full form, which further activates target transcription. Pathological roles of $\mathrm{SHH}$, Indian hedgehog $(\mathrm{IHH})$, and BDNF have been suggested in

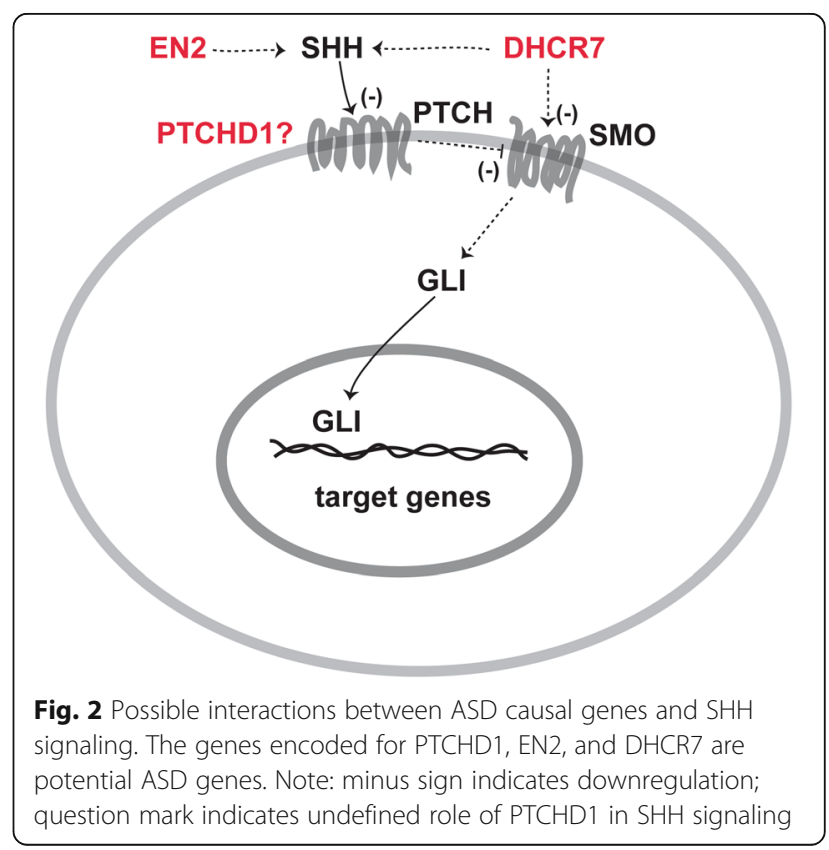


children with ASD [14]. SHH signaling influences neurogenesis and neural patterning during the development of the central nervous system. Dysregulation of SHH signaling in the brain leads to neurological disorders like ASD [15]. SHH has also been associated with oxidative stress in autism [107]. Significantly higher levels of oxygen free radicals (OFR) and serum SHH protein have been demonstrated in autistic children, suggesting a pathological role of oxidative stress and SHH in ASD [108]. Figure 2 summarizes the interaction between ASD causal genes and SHH signaling.

PTCHD1 Mutations in the gene patched domain-containing 1 (PTCHD1) have been reported in ASD and ID patients [109]. Ptchd1 KO male mice exhibit cognitive alterations [109]. LOF experiments do not support a role for PTCHD1 protein in SHH-dependent signaling but reveal a disruption of synaptic transmission in the mouse dentate gyrus [109]. PTCHD1 has been shown to bind with the post-synaptic proteins PSD95 and SAP102 [110]. Ptchd1 deficiency in male mice (Ptchd $1^{-/ y}$ ) induces global changes in synaptic gene expression, affects the expression of the immediate-early expression genes Egr1 and Npas4, and impairs excitatory synaptic structure and neuronal excitatory activity in the hippocampus, leading to cognitive dysfunction, motor disabilities, and hyperactivity [110].

DHCR7 The impaired function of the cholesterol biosynthetic enzyme 7-dehydrocholesterol reductase (DHCR7) has been associated with the ASD [111]. The activation of the transmembrane protein Smoothened (SMO), through which $\mathrm{SHH}$ signaling is transduced, and its localization to the primary cilium is affected by conditions of reduced cholesterol biosynthesis [111].

EN2 The transcription factor engrailed2 (EN2) has been associated with ASD [112-116]. The increased levels of EN2 in affected individuals with EN2 ASD-associated haplotype (rs1861972-rs1861973 A-C) further support the susceptibility of EN2 gene for ASD [77, 117, 118]. The increased EN2 levels result in the elevated levels of the $S H H$ expression as reported in post-mortem samples [117]. $S H H$ is one of the genes flanking EN2 which is coexpressed during brain development $[119,120]$.

\section{Altered FGF signaling in ASD}

FGF signaling plays a crucial role in brain patterning, and its malfunction can result in various neurological disorders [121]. There are 18 secreted FGFs and 4 tyrosine kinase FGF receptors (FGFRs) reported in the mammalian FGF family whose interaction is regulated by cofactors and extracellular binding proteins [122].
Activation of FGFRs leads to the phosphorylation of tyrosine residues which further results in the interaction between cytosolic adaptor proteins and the RAS-MAPK, PI3K-AKT, PLC $\gamma$, and STAT intracellular signaling pathways [122]. Dysregulation of FGF signaling has been suggested to play a role in the pathogenesis of ASD [16]. For instance, cortical abnormalities observed in autistic brains have been associated with defective FGF signaling $[121,123]$. Perturbations in the number of excitatory and inhibitory synapses have been implicated in ASD [124]. Mutant mice lacking FGF22 or FGF7, which displayed impaired synapse formation in the hippocampal CA3 pyramidal neurons, have been reported [124], supporting the pathological role of dysregulated FGF signaling in ASD (Table 1). The metabotropic glutamate receptor 5 ( $m$ GluR5) LOF results in aberrant dendritogenesis, one of the characteristics observed in autistic brains, in the cortical neurons by increasing nerve growth factor (NGF) and FGF10 mRNA levels [125] (Table 1).

\section{Altered retinoic acid signaling in ASD}

Retinoic acid (RA), the functional metabolite of vitamin $\mathrm{A}$, is an essential morphogen in vertebrate development [126, 127]. RA mediates both genomic transcriptional effects by binding to nuclear receptors called retinoic acid receptors (RARs) and retinoid X receptors (RXRs) as well as non-genomic effects such as retinoylation (RA acylation), a post-translational modification of proteins $[128,129]$. A range of co-activators and co-repressors have been reported in modulating RA signaling activity [129]. In the developing CNS, RA is required for neural patterning, differentiation, proliferation, and the establishment of neurotransmitter systems [130]. RA from the meninges regulates cortical neuron generation [131]. Vitamin A deficiency may induce ASD-like behaviors in rats [132]. It has been proposed that an abnormality in the interplay between retinoic acid and sex hormones may cause ASD [19]. Aberrant methylation and decreased protein expression of retinoic acid-related orphan receptor alpha (RORA) have been found in the autistic brain [133], while RORA variants have been associated with ASD [134]. Whole-exome sequencing in a South American cohort links RA signaling genes, including an RA-synthesizing gene aldehyde dehydrogenase 1 family member A3 (ALDH1A3) and the RORA-regulated FOXN1 to ASD [135]. Low level of ALDH1A1 has been found in a subset of autistic patients [136]. De novo mutations in arginine-glutamic acid dipeptide repeats (RERE) that encode a nuclear receptor coregulator for RA signaling may cause ASD and other defects associated with proximal 1p36 deletions [137]. Genome-wide chromatin immunoprecipitation analysis revealed that RORA transcriptionally regulates several ASD-relevant genes, including NLGN1 [138]. Intriguingly, 
overexpression of UBE3A represses ALDH1A2 and impairs RA-mediated synaptic plasticity in ASD, which can be alleviated by RA supplements [139]. All-trans-RA can upregulate the reduced CD38 expression in lymphoblastoid cell lines from ASD, while CD38-deficient mice exhibit ASD-like behavior [140, 141]. Beta-carotene, a precursor of vitamin $\mathrm{A}$, has been shown as a potential treatment of autistic-like behavior in BTBR mice [142]. A synthetic RORA/G agonist has been tested to alleviate autistic disorders in a mouse model [143]. These studies suggest therapeutic approaches for treating ASD by targeting RA and related signaling pathways. The possible interactions among ASD causal genes and RA signaling have been described in Fig. 3.

\section{Non-genetic etiologies of ASD and altered signaling pathways}

Various exogenous factors, such as prenatal exposure to viral infection or VPA, lead to several neurodevelopmental disorders with perturbed WNT signaling (Fig. 1). The transcription factor GATA-3 is critical for the brain development [144] and is involved in the WNT [145] and TGF- $\beta / B M P ~[146,147]$ signaling pathways. An increase in binding to GATA sites in DNA has been reported while exposure to thalidomide, valproate, and alcohol is known to cause ASD [148].

Viral infection The infection with rubella in early pregnancy has been linked to autism in clinical and epidemiological studies [149]. Prenatal viral-like immune activation has recently been reported to induce stable hyper- and hypomethylated CpGs at WNT signaling genomic regions (WNT3, WNT7B, WNT8A) which further disrupt the transcription of downstream target genes [150], suggesting a potential role of epigenetic modulation of WNT signaling in ASD etiologies.

VPA The use of the anticonvulsant valproic acid (VPA) during early pregnancy has been reported to cause autism in $11 \%$ children and autistic traits in an even larger number of children [151]. VPA is used in the treatment of epilepsy and bipolar disorder. However, rat prenatal exposure to VPA results in animals that are susceptible to autism-like phenotypes [20]. Prenatally VPA-treated rats exhibit an imbalance in oxidative homeostasis that facilitates susceptibility to autism [20, 152]. VPA treatment in rats resulted in lowered social interaction, longer moving time in the central area, and reduced standing times. Sulindac is a small molecule inhibitor of the $\mathrm{WNT} / \beta$-catenin signaling pathway $[20,152]$. Sulindac treatment can correct the VPA-induced autistic-like behaviors, p-Gsk3 $\beta$ downregulation, and $\beta$-catenin upregulation in the prefrontal lobe, hippocampus, and cerebellum [152].

\section{Conclusions}

ASD causal genes may act upstream or downstream of WNT, BMP/TGF $\beta$, SHH, FGF, and RA signaling

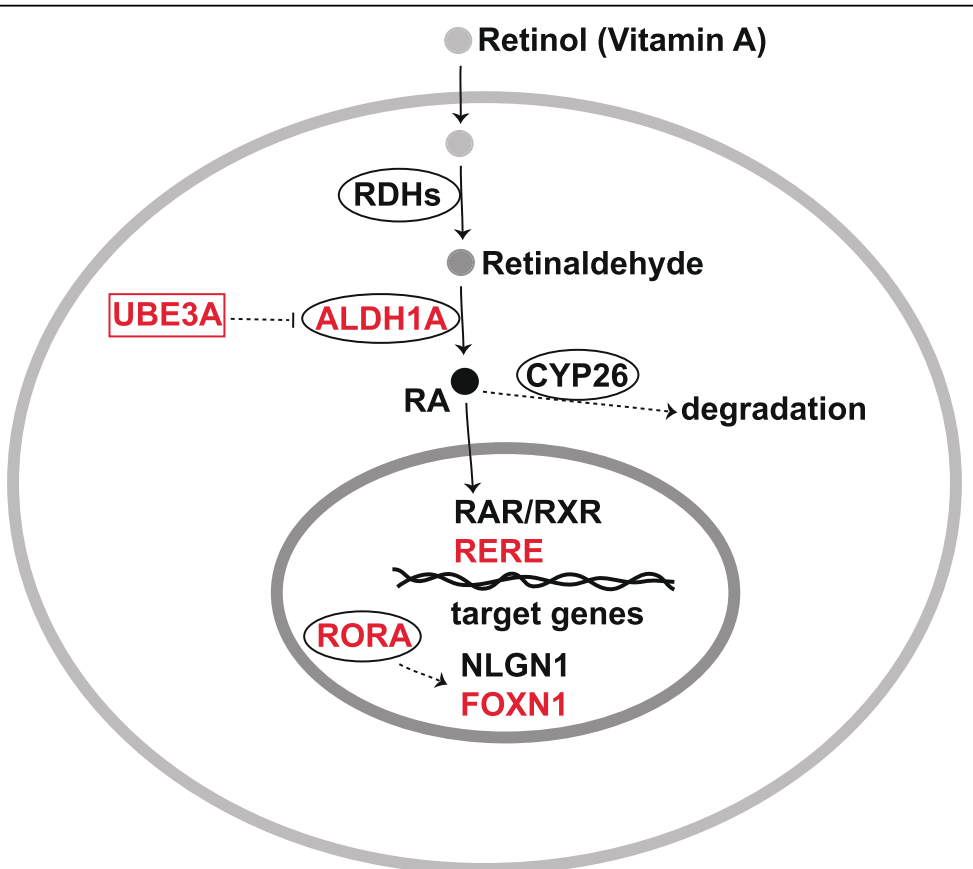

Fig. 3 Possible interactions between ASD causal genes and RA signaling. UBE3A affects ALDH1A expression and thereby affects retinoic acid signaling pathway. RORA is associated with ASD which influences NLGN1. The RA signaling coregulator RERE is also associated with ASD 
pathways in vertebrates and invertebrates (Table 1 and Figs. 1, 2, 3, and 4). Alteration in these signaling pathways during brain development seems to cause ASD and other neurodevelopmental disorders. Previous studies support possible roles for these signaling pathways in the design of therapeutic targets for autism. However, systematic developmental studies are required to identify the temporal window in which impairment of these signals has the most significant impact on brain structure and function and resulting behavioral impairment. Such studies may also help in elucidating the upstream and downstream signaling pathways in the etiology of neurodevelopmental disorders as well as the mechanisms behind a particular impaired behavior. Although crosstalk among signaling pathways has been reported in several developmental processes and related diseases, similar studies in autistic models are lacking. Crosstalk between WNT and Hedgehog/Gli signaling in colon cancer has been studied and suggested as a potential target for its treatment [153]. $\beta$-Catenin and Gli1 are negatively regulated by GSK3 $\beta$ and CK1 $\alpha$ [154-156] and have antagonistic roles in regulating TCF and downstream target genes in metastatic colon cancer [157]. The suppressor of the fused kinase (Sufu), a negative regulator of Gli1, has been reported to regulate the distribution of $\beta$-catenin in the nucleus and cytoplasm [158-160]. In colon cancer, loss of either PTEN or p53 leads to the activation of both $\beta$-catenin and Gli1 $[157,161]$. The inhibition of SMO, an upstream active factor of Gli1, has been shown to reduce active $\beta$-catenin levels and induce its nuclear exclusion [162]. Gli1 negatively regulates Gli3R and vice versa [157]. Further, Gli3R has been shown to inhibit the activity of $\beta$-catenin [163]. The transcription of Wnt2b, Wnt4, and $W n t 7 b$ is shown to be induced by Gli1 [164]. The crosstalk between TGF- $\beta$ and SHH pathways has also been reported in cancer [165], as well as in cyclosporine-enhanced cell proliferation in human gingival fibroblasts [166]. Neuropilin-1 (NRP1), a TGF- $\beta$ co-receptor expressed on the membrane of cancer cells, is known to enhance the canonical SMAD2/3 signaling in

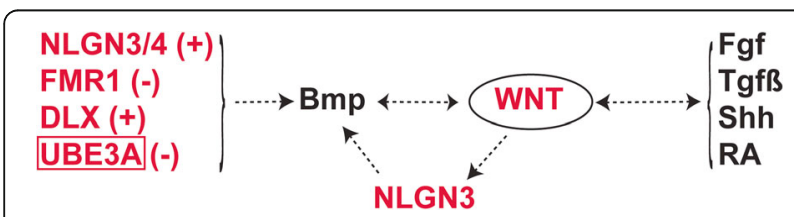

Fig. 4 ASD causal genes affecting BMP signaling and potential crosstalk with other signaling pathways. ASD causal genes-encoded proteins, such as NLGN3/4, FMR1, DLX, and UBE3A, interact with BMP signaling pathway which may further affect WNT signaling. It should be noted that overexpression of UBE3A affects WNT and RA signaling pathways. However, its loss-of-function affects BMP signaling. Note: plus sign indicates upregulation; minus sign indicates downregulation response to TGF- $\beta$ [167]. Further, HH signaling increases NRP1 transcription and NRP1 is also reported to increase the activation of $\mathrm{HH}$ target genes by mediating $\mathrm{HH}$ transduction between activated SMO and SUFU $[168,169]$. While TGF- $\beta$ is important for SMO-mediated cancer development [170], its role in the induction of GLI2 and GLI1 expression by inhibition of PKA activity has also been reported [171]. A hierarchical pattern of crosstalk has been suggested in which TGF- $\beta$ upregulates Shh and leads to cyclosporine-enhanced Shh expression and cell proliferation in gingival fibroblasts [166]. Crosstalk between FGF and WNT pathways has been observed in zebrafish tailbud [172] and mouse craniofacial development [173]. Reciprocal positive regulation between FGF and WNT signaling has been observed [172]. WNT/ $\beta$-catenin signaling in the anterior neural ridge and facial ectoderm has been shown to positively target Fgf8, and $\beta$-catenin GOF leads to ectopic expression of Fgf8 in the facial ectoderm [173]. Wnt has been reported to increase FGF signaling within the Mapk branch by elevating Erk phosphorylation levels [172]. Further, Fgf has been shown to inhibit the Wnt antagonists, dkk1 and notum1a, resulting in the elevation of WNT signaling [172]. A LOF mutation in $U B E 3 A$, an ASD-associated gene, influences both the WNT and BMP signaling pathways, suggesting possible crosstalk between them [12, 78]. Xu et al. further demonstrated that excessive $U B E 3 A$ impairs RA-mediated neuronal synaptic plasticity in ASD probably by negative regulation of ALDH1A2, the rate-limiting enzyme of retinoic acid (RA) synthesis. [139]. Medina et al. [81] suggested that while Nlgn3 is a direct target of WNT/ $\beta$-catenin signaling, the ASD-associated gene may also regulate BMP signaling. These results suggest that signaling crosstalk among morphogenetic pathways is mediated by autistic causal genes, thereby demonstrating value in further in-depth studies on interactions between signaling molecules in normal physiological and diseased conditions. Evidence has suggested a tissue-specific mechanism behind WNT and BMP signaling crosstalk [174]. Moreover, WNT signaling may repress RA signaling during orofacial development [175], while WNT signaling positively regulates RA signaling in the dorsal optic cup during eye development [176], suggesting context-dependent mechanisms of signaling interactions. Therefore, the interaction between various signaling pathways should be studied in neuronal as well as glial cells for ASD, which may help in designing treatment and targeting perturbed signaling in a cell-specific manner. Among the nine high-confidence ASD risk genes, only a few have been studied so far in the context of impaired signaling pathways. The investigation of roles for other ASD genes in neurodevelopment and in the regulation of various signaling pathways may increase the understanding of mechanisms behind the etiology of ASD. Overall, this article 
proposes to study how different ASD causal genes interact with each signaling pathway in the development of the brain and whether there is any crosstalk between them.

\section{Abbreviations}

AIS: Axon initial segment; ALDH1A3: Aldehyde dehydrogenase 1 family member A3; ANK3: Ankyrin-G; APC: Adenomatous polyposis coli; ASD: Autism spectrum disorder; BDNF: Brain-derived neurotrophic factor; BMP: Bone morphogenetic protein; Bmper: BMP binding endothelial regulator; BMPR2: Bone morphogenetic protein type II receptor; CHD8: Chromodomain helicase DNA-binding protein 8; CKO: Conditional knockout; CTNNB1: $\beta$-Catenin; DHCR7: 7-Dehydrocholesterol reductase; DIXDC1: DIX domain containing 1; DNIg4: Drosophila neuroligin 4; DNVs: De novo variants; EN2: Engrailed2; FGF: Fibroblast growth factor; FMR1: Fragile X mental retardation 1; FMRP: FMR1 protein; FXS: Fragile X syndrome; GOF: Gain-of-function; hiPSC: Human induced pluripotent stem cell; IHH: Indian hedgehog; LIMK1: LIM domain kinase 1; LOF: Loss-of-function; mGluR5: Metabotropic glutamate receptor 5; NAc: Nucleus accumbens; NGF: Nerve growth factor; NGSEA: Network-based gene set enrichment analysis; NLGN: Neuroligins; Nlgn3: Neuroligin 3; NMJs: Neuromuscular junctions; OFR: Oxygen free radicals; PCP: Planar cel polarity; PGE2: Prostaglandin E2; PTCHD1: Patched domain-containing 1; RA: Retinoic acid; RERE: Arginine-glutamic acid dipeptide repeats; RORA: Retinoic acid-related orphan receptor alpha; $\mathrm{SHH}$ : Sonic hedgehog; SMO: Transmembrane protein Smoothened; TGF- $\beta$ : Transforming growth factor $\beta$; Tkv: BMP type I receptor thickvein; UBE3A: Ubiquitin-protein ligase E3A; VPA: Valproic acid

\section{Acknowledgements}

We appreciate the technical assistance from Rebecca Donham, Yue Liu, and Taylor Imai during the manuscript preparation.

\section{Funding}

The Zhou Laboratory is supported by grants from the NIH (R01NS102261 and R01DE026737 to CZ) and the Shriners Hospitals for Children (85105 and 86600 to CZ).

\section{Availability of data and materials}

Not applicable.

\section{Authors' contributions}

KS conceptualized the subject, reviewed the literature, and wrote the draft manuscript. $K R, Y J, R G$, and $S R$ assisted in the manuscript preparation. CZ initiated the topic, designed the figures, and revised and finalized the manuscript. All authors read and approved the final manuscript.

\section{Ethics approval and consent to participate}

Not applicable.

\section{Consent for publication}

Not applicable.

\section{Competing interests}

The authors declare that they have no competing interests.

\section{Publisher's Note}

Springer Nature remains neutral with regard to jurisdictional claims in published maps and institutional affiliations.

Received: 27 July 2018 Accepted: 2 May 2019

Published online: 15 June 2019

\section{References}

1. Mohn JL, Alexander J, Pirone A, Palka CD, Lee SY, Mebane L, et al. Adenomatous polyposis coli protein deletion leads to cognitive and autismlike disabilities. Mol Psychiatry. 2014;19:1133-42.

2. Golden CE, Buxbaum JD, De Rubeis S. Disrupted circuits in mouse models of autism spectrum disorder and intellectual disability. Curr Opin Neurobiol. 2017:48:106-12.
3. Werling DM, Brand H, An JY, Stone MR, Zhu L, Glessner JT, et al. An analytical framework for whole-genome sequence association studies and its implications for autism spectrum disorder. Nat Genet. 2018;50:727-36.

4. Kosmicki JA, Samocha KE, Howrigan DP, Sanders SJ, Slowikowski K, Lek M, et al. Refining the role of de novo protein-truncating variants in neurodevelopmental disorders by using population reference samples. Nat Genet. 2017:49:504-10.

5. Willsey AJ, Sanders SJ, Li M, Dong S, Tebbenkamp AT, Muhle RA, et al. Coexpression networks implicate human midfetal deep cortical projection neurons in the pathogenesis of autism. Cell. 2013;155:997-1007.

6. Cotney J, Muhle RA, Sanders SJ, Liu L, Willsey AJ, Niu W, et al. The autismassociated chromatin modifier CHD8 regulates other autism risk genes during human neurodevelopment. Nat Commun. 2015;6:6404.

7. Bae SM, Hong JY. The Wnt signaling pathway and related therapeutic drugs in autism spectrum disorder. Clin Psychopharmacol Neurosci. 2018;16:129-35

8. Kalkman HO. A review of the evidence for the canonical Wnt pathway in autism spectrum disorders. Mol Autism. 2012;3:10.

9. Mulligan KA, Cheyette BNR. Neurodevelopmental perspectives on Wnt signaling in psychiatry. Mol Neuropsychiatry. 2016;2:219-46.

10. Zhang X, Rui M, Gan G, Huang C, Yi J, Lv H, et al. Neuroligin 4 regulates synaptic growth via the bone morphogenetic protein (BMP) signaling pathway at the Drosophila neuromuscular junction. J Biol Chem. 2017;292:17991-8005.

11. Kashima R, Roy S, Ascano M, Martinez-Cerdeno V, Ariza-Torres J, Kim S, et al. Augmented noncanonical BMP type II receptor signaling mediates the synaptic abnormality of fragile X syndrome. Sci Signal. 2016;9:ra58.

12. Li W, Yao A, Zhi H, Kaur K, Zhu YC, Jia M, et al. Angelman syndrome protein Ube3a regulates synaptic growth and endocytosis by inhibiting BMP signaling in Drosophila. PLoS Genet. 2016;12:e1006062.

13. Sajan SA, Rubenstein JLR, Warchol ME, Lovett M. Identification of direct downstream targets of Dlx5 during early inner ear development. Hum Mol Genet. 2011:20:1262-73.

14. Halepoto DM, Bashir S, Zeina R, Al-Ayadhi LY. Correlation between hedgehog $(\mathrm{Hh})$ protein family and brain-derived neurotrophic factor (BDNF) in autism spectrum disorder (ASD). J Coll Physicians Surg Pak. 2015;25:882-5.

15. Patel SS, Tomar S, Sharma D, Mahindroo N, Udayabanu M. Targeting sonic hedgehog signaling in neurological disorders. Neurosci Biobehav Rev. 2017;74:76-97.

16. Iwata T, Hevner RF. Fibroblast growth factor signaling in development of the cerebral cortex. Develop Growth Differ. 2009;51:299-323.

17. Ansari MA, Attia SM, Nadeem A, Bakheet SA, Raish M, Khan TH, et al. Activation of adenosine $A 2 A$ receptor signaling regulates the expression of cytokines associated with immunologic dysfunction in BTBR T+ltpr3tf/J mice. Mol Cell Neurosci. 2017:82:76-87.

18. Chen R, Davis LK, Guter S, Wei Q, Jacob S, Potter MH, et al. Leveraging blood serotonin as an endophenotype to identify de novo and rare variants involved in autism. Mol Autism. 2017:8:14

19. Niculae AS, Pavăl D. From molecules to behavior: an integrative theory of autism spectrum disorder. Med Hypotheses. 2016;97:74-84

20. Zhang $Y$, Sun $Y$, Wang F, Wang Z, Peng Y, Li R. Downregulating the canonical Wnt/ $\beta$-catenin signaling pathway attenuates the susceptibility to autism-like phenotypes by decreasing oxidative stress. Neurochem Res. 2012:37:1409-19.

21. Tang SJ. Synaptic activity-regulated Wnt signaling in synaptic plasticity, glial function and chronic pain. CNS Neurol Disord Drug Targets. 2014; 13:737-44.

22. Wada $\mathrm{H}$, Okamoto $\mathrm{H}$. Roles of noncanonical Wnt/PCP pathway genes in neuronal migration and neurulation in zebrafish. Zebrafish. 2009;6:3-8.

23. Wodarz A, Nusse R. Mechanisms of Wnt signaling in development. Annu Rev Cell Dev Biol. 1998;14:59-88.

24. Rosso SB, Inestrosa NC. WNT signaling in neuronal maturation and synaptogenesis. Front Cell Neurosci. 2013;7:103.

25. Bielen $H$, Houart $C$. The Wnt cries many: Wnt regulation of neurogenesis through tissue patterning, proliferation, and asymmetric cell division. Dev Neurobiol. 2014;74:772-80.

26. Abu-Khalil A, Fu L, Grove EA, Zecevic N, Geschwind DH. Wht genes define distinct boundaries in the developing human brain: implications for human forebrain patterning. J Comp Neurol. 2004;474:276-88.

27. Bengoa-Vergniory N, Kypta RM. Canonical and noncanonical Wnt signaling in neural stem/progenitor cells. Cell Mol Life Sci. 2015;72:4157-72. 
28. Burden $\mathrm{SJ}$. Wnts as retrograde signals for axon and growth cone differentiation. Cell. 2000;100:495-7.

29. Inestrosa NC, Varela-Nallar L. Wnt signalling in neuronal differentiation and development. Cell Tissue Res. 2015;359:215-23.

30. Onishi $\mathrm{K}$, Hollis E, Zou Y. Axon guidance and injury-lessons from Wnts and Wnt signaling. Curr Opin Neurobiol. 2014;27:232-40.

31. Okerlund ND, Cheyette BNR. Synaptic Wnt signaling-a contributor to major psychiatric disorders. J Neurodev Disord. 2011;3:162-74.

32. Oron O, Elliott E. Delineating the common biological pathways perturbed by ASD's genetic etiology: lessons from network-based studies. Int J Mol Sci. 2017;18:828.

33. Kwan V, Unda BK, Singh KK. Wnt signaling networks in autism spectrum disorder and intellectual disability. J Neurodev Disord. 2016;8:45.

34. Martin PM, Yang X, Robin N, Lam E, Rabinowitz JS, Erdman CA, et al. A rare WNT1 missense variant overrepresented in ASD leads to increased WNT signal pathway activation. Transl Psychiatry. 2013;3:e301.

35. Hormozdiari F, Penn O, Borenstein E, Eichler EE. The discovery of integrated gene networks for autism and related disorders. Genome Res. 2015;25:142-54.

36. Krumm N, O'Roak BJ, Shendure J, Eichler EE. A de novo convergence of autism genetics and molecular neuroscience. Trends Neurosci. 2014;37:95-105.

37. Grainger S, Willert K. Mechanisms of Wnt signaling and control. Wiley Interdiscip Rev Syst Biol Med. 2018:e1422.

38. Komiya Y, Habas R. Wht signal transduction pathways. Organogenesis. 2008:4:68-75.

39. O'Roak BJ, Vives L, Girirajan S, Karakoc E, Krumm N, Coe BP, et al. Sporadic autism exomes reveal a highly interconnected protein network of de novo mutations. Nature. 2012:485:246-50.

40. Sowers $L P, L o o L$, Wu Y, Campbell E, Ulrich JD, Wu S, et al. Disruption of the noncanonical Wnt gene PRICKLE2 leads to autism-like behaviors with evidence for hippocampal synaptic dysfunction. Mol Psychiatry. 2013;18:1077-89.

41. Wassink TH, Piven J, Vieland VJ, Huang J, Swiderski RE, Pietila J, et al. Evidence supporting WNT2 as an autism susceptibility gene. Am J Med Genet. 2001:105:406-13.

42. Marui T, Funatogawa I, Koishi S, Yamamoto K, Matsumoto H, Hashimoto O, et al. Association between autism and variants in the wingless-type MMTV integration site family member 2 (WNT2) gene. Int J Neuropsychopharmacol. 2010;13:443-9.

43. Lin PI, Chien YL, Wu YY, Chen CH, Gau SS, Huang YS, et al. The WNT2 gene polymorphism associated with speech delay inherent to autism. Res Dev Disabil. 2012;33:1533-40.

44. Levy D, Ronemus M, Yamrom B, Lee Y, Leotta A, Kendall J, et al. Rare de novo and transmitted copy-number variation in autistic spectrum disorders. Neuron. 2011;70:886-97.

45. Chow ML, Pramparo T, Winn ME, Barnes CC, Li HR, Weiss L, et al. Agedependent brain gene expression and copy number anomalies in autism suggest distinct pathological processes at young versus mature ages. PLoS Genet. 2012;8:e1002592.

46. Thomas KR, Capecchi MR. Targeted disruption of the murine int-1 protooncogene resulting in severe abnormalities in midbrain and cerebellar development. Nature. 1990:346:847-50.

47. McMahon AP, Bradley A. The Wnt-1 (int-1) proto-oncogene is required for development of a large region of the mouse brain. Cell. 1990;62:1073-85.

48. McMahon AP, Joyner AL, Bradley A, McMahon JA. The midbrain-hindbrain phenotype of Wnt-1-Wnt-1- mice results from stepwise deletion of engrailed-expressing cells by 9.5 days postcoitum. Cell. 1992;69:581-95.

49. Hiester BG, Galati DF, Salinas PC, Jones KR. Neurotrophin and Wnt signaling cooperatively regulate dendritic spine formation. Mol Cell Neurosci. 2013;56:115-27.

50. Lie DC, Colamarino SA, Song HJ, Désiré L, Mira H, Consiglio A, et al. Wnt signalling regulates adult hippocampal neurogenesis. Nature. 2005;437:1370-5.

51. Liu P, Wakamiya M, Shea MJ, Albrecht U, Behringer RR, Bradley A. Requirement for Wnt3 in vertebrate axis formation. Nat Genet. 1999;22:361-5.

52. Fazel Darbandi S, Robinson Schwartz SE, Qi Q, Catta-Preta R, Pai EL, Mandell JD, et al. Neonatal Tbr1 dosage controls cortical layer 6 connectivity. Neuron. 2018:100:831-845.e7.

53. Jin YR, Han XH, Taketo MM, Yoon JK. Wnt9b-dependent FGF signaling is crucial for outgrowth of the nasal and maxillary processes during upper jaw and lip development. Development. 2012;139:1821-30.

54. Juriloff DM, Harris MJ, McMahon AP, Carroll TJ, Lidral AC. Wnt9b is the mutated gene involved in multifactorial nonsyndromic cleft lip with or without cleft palate in AWySn mice, as confirmed by a genetic complementation test. Birth Defects Res A Clin Mol Teratol. 2006;76:574-9.

55. MacDonald BT, He X. Frizzled and LRP5/6 receptors for Wnt/ $\beta$-catenin signaling. Cold Spring Harb Perspect Biol. 2012:4:a007880.

56. MacDonald BT, Tamai K, He X. Wnt/beta-catenin signaling: components, mechanisms, and diseases. Dev Cell. 2009:17:9-26.

57. Zhou XL, Giacobini M, Anderlid BM, Anckarsäter H, Omrani D, Gillberg C, et al. Association of adenomatous polyposis coli (APC) gene polymorphisms with autism spectrum disorder (ASD). Am J Med Genet B Neuropsychiatr Genet. 2007;144B:351-4.

58. Barber JC, Ellis KH, Bowles LV, Delhanty JD, Ede RF, Male BM, et al. Adenomatous polyposis coli and a cytogenetic deletion of chromosome 5 resulting from a maternal intrachromosomal insertion. J Med Genet. 1994;31:312-6.

59. Clevers H, Nusse R. Wnt/B-catenin signaling and disease. Cell. 2012;149:1192-205.

60. Grigoryan T, Wend P, Klaus A, Birchmeier W. Deciphering the function of canonical Wnt signals in development and disease: conditional lossand gain-of-function mutations of beta-catenin in mice. Genes Dev. 2008;22:2308-41.

61. Kuechler A, Willemsen MH, Albrecht B, Bacino CA, Bartholomew DW, van Bokhoven $\mathrm{H}$, et al. De novo mutations in beta-catenin (CTNNB1) appear to be a frequent cause of intellectual disability: expanding the mutational and clinical spectrum. Hum Genet. 2015;134:97-109.

62. O'Roak BJ, Vives L, Fu W, Egertson JD, Stanaway IB, Phelps IG, et al. Multiplex targeted sequencing identifies recurrently mutated genes in autism spectrum disorders. Science. 2012;338:1619-22.

63. Sanders SJ, Murtha MT, Gupta AR, Murdoch JD, Raubeson MJ, Willsey AJ, et al. De novo mutations revealed by whole-exome sequencing are strongly associated with autism. Nature. 2012;485:237-41.

64. Dubruc E, Putoux A, Labalme A, Rougeot C, Sanlaville D, Edery P. A new intellectual disability syndrome caused by CTNNB1 haploinsufficiency. Am J Med Genet A. 2014;164A:1571-5.

65. Zhao T, Gan Q, Stokes A, Lassiter RNT, Wang Y, Chan J, et al. $\beta$-Catenin regulates Pax3 and $\mathrm{Cd} \times 2$ for caudal neural tube closure and elongation. Development. 2014;141:148-57.

66. Dong F, Jiang J, McSweeney C, Zou D, Liu L, Mao Y. Deletion of CTNNB1 in inhibitory circuitry contributes to autism-associated behavioral defects. Hum Mol Genet. 2016;25:2738-51.

67. Grant SFA, Thorleifsson G, Reynisdottir I, Benediktsson R, Manolescu A, Sainz J, et al. Variant of transcription factor 7-like 2 (TCF7L2) gene confers risk of type 2 diabetes. Nat Genet. 2006;38:320-3.

68. De Rubeis $\mathrm{S}$, He X, Goldberg AP, Poultney CS, Samocha K, Cicek AE, et al. Synaptic, transcriptional and chromatin genes disrupted in autism. Nature. 2014:515:209-15.

69. Iossifov I, O'Roak BJ, Sanders SJ, Ronemus M, Krumm N, Levy D, et al. The contribution of de novo coding mutations to autism spectrum disorder. Nature. 2014;515:216-21.

70. Zhou CJ, Pinson KI, Pleasure SJ. Severe defects in dorsal thalamic development in low-density lipoprotein receptor-related protein-6 mutants. J Neurosci. 2004:24:7632-9.

71. Lee M, Yoon J, Song H, Lee B, Lam DT, Yoon J, et al. Tcf7l2 plays crucial roles in forebrain development through regulation of thalamic and habenular neuron identity and connectivity. Dev Biol. 2017;424:62-76.

72. Okumura A, Yamamoto T, Miyajima M, Shimojima K, Kondo S, Abe S, et al. $3 p$ interstitial deletion including PRICKLE2 in identical twins with autistic features. Pediatr Neurol. 2014;51:730-3.

73. Nagaoka T, Tabuchi K, Kishi M. PDZ interaction of Vangl2 links PSD-95 and Prickle2 but plays only a limited role in the synaptic localisation of Vangl2. Sci Rep. 2015;5:12916.

74. Fujimura L, Watanabe-Takano H, Sato Y, Tokuhisa T, Hatano M. Prickle promotes neurite outgrowth via the Dishevelled dependent pathway in C1300 cells. Neurosci Lett. 2009:467:6-10.

75. Shi L, Zhang X, Golhar R, Otieno FG, He M, Hou C, et al. Whole-genome sequencing in an autism multiplex family. Mol Autism. 2013;4:8

76. Iqbal Z, Vandeweyer $G$, van der Voet M, Waryah AM, Zahoor MY, Besseling JA, et al. Homozygous and heterozygous disruptions of ANK3: at the crossroads of neurodevelopmental and psychiatric disorders. Hum Mol Genet. 2013;22:1960-70.

77. Bi C, Wu J, Jiang T, Liu Q, Cai W, Yu P, et al. Mutations of ANK3 identified by exome sequencing are associated with autism susceptibility. Hum Mutat. 2012;33:1635-8

78. Yi JJ, Paranjape SR, Walker MP, Choudhury R, Wolter JM, Fragola G, et al. The autism-linked UBE3A T485A mutant E3 ubiquitin ligase activates 
the Wnt/ß-catenin pathway by inhibiting the proteasome. J Biol Chem. 2017:292:12503-15.

79. Kwan V, Meka DP, White SH, Hung CL, Holzapfel NT, Walker S, et al. DIXDC1 phosphorylation and control of dendritic morphology are impaired by rare genetic variants. Cell Rep. 2016;17:1892-904.

80. Wong CT, Ussyshkin N, Ahmad E, Rai-Bhogal R, Li H, Crawford DA. Prostaglandin E2 promotes neural proliferation and differentiation and regulates Wht target gene expression. J Neurosci Res. 2016;94:759-75.

81. Medina MA, Andrade VM, Caracci MO, Avila ME, Verdugo DA, Vargas MF, et al. Wnt/ $\beta$-catenin signaling stimulates the expression and synaptic clustering of the autism-associated Neuroligin 3 gene. Transl Psychiatry. 2018;8:45.

82. Hedstrom KL, Ogawa Y, Rasband MN. AnkyrinG is required for maintenance of the axon initial segment and neuronal polarity. J Cell Biol. 2008;183:635-40.

83. Kordeli E, Lambert $\mathrm{S}$, Bennett $\mathrm{V}$. AnkyrinG. A new ankyrin gene with neuralspecific isoforms localized at the axonal initial segment and node of Ranvier. J Biol Chem. 1995;270:2352-9.

84. Kizhatil K, Davis JQ, Davis L, Hoffman J, Hogan BLM, Bennett V. Ankyrin-G is a molecular partner of E-cadherin in epithelial cells and early embryos. J Biol Chem. 2007;282:26552-61.

85. Durak O, de Anda FC, Singh KK, Leussis MP, Petryshen TL, Sklar P, et al. Ankyrin-G regulates neurogenesis and Wnt signaling by altering the subcellular localization of $\beta$-catenin. Mol Psychiatry. 2015;20:388-97.

86. Thompson BA, Tremblay V, Lin G, Bochar DA. CHD8 is an ATP-dependent chromatin remodeling factor that regulates beta-catenin target genes. Mol Cell Biol. 2008:28:3894-904.

87. Nishiyama M, Oshikawa K, Tsukada Y, Nakagawa T, lemura S, Natsume T, et al. CHD8 suppresses p53-mediated apoptosis through histone $\mathrm{H1}$ recruitment during early embryogenesis. Nat Cell Biol. 2009;11:172-82.

88. Subtil-Rodríguez A, Vázquez-Chávez E, Ceballos-Chávez M, RodríguezParedes M, Martín-Subero Jl, Esteller M, et al. The chromatin remodeller CHD8 is required for E2F-dependent transcription activation of S-phase genes. Nucleic Acids Res. 2014;42:2185-96.

89. Platt RJ, Zhou Y, Slaymaker IM, Shetty AS, Weisbach NR, Kim JA, et al. Chd8 mutation leads to autistic-like behaviors and impaired striatal circuits. Cell Rep. 2017:19:335-50

90. Wilkinson B, Grepo N, Thompson BL, Kim J, Wang K, Evgrafov OV, et al. The autism-associated gene chromodomain helicase DNA-binding protein 8 (CHD8) regulates noncoding RNAs and autism-related genes. Transl Psychiatry. 2015;5:e568.

91. Martin PM, Stanley RE, Ross AP, Freitas AE, Moyer CE, Brumback AC, et al. DIXDC1 contributes to psychiatric susceptibility by regulating dendritic spine and glutamatergic synapse density via GSK3 and Wnt/3-catenin signaling. Mol Psychiatry. 2018;23:467-75.

92. Kivimäe S, Martin PM, Kapfhamer D, Ruan Y, Heberlein U, Rubenstein JLR, et al. Abnormal behavior in mice mutant for the Disc1 binding partner, Dixdc1. Transl Psychiatry. 2011;1:e43.

93. Bandim JM, Ventura LO, Miller MT, Almeida HC, Costa AES. Autism and Möbius sequence: an exploratory study of children in northeastern Brazil. Arq Neuropsiquiatr. 2003;61:181-5.

94. Landrigan PJ. What causes autism? Exploring the environmental contribution. Curr Opin Pediatr. 2010;22:219-25.

95. Jamain S, Quach $\mathrm{H}$, Betancur C, Råstam M, Colineaux C, Gillberg IC, et al. Mutations of the X-linked genes encoding neuroligins NLGN3 and NLGN4 are associated with autism. Nat Genet. 2003;34:27-9.

96. Zi Z, Chapnick DA, Liu X. Dynamics of TGF- $\beta /$ Smad signaling. FEBS Lett. 2012;586:1921-8.

97. Lowery JW, Rosen V. Bone morphogenetic protein-based therapeutic approaches. Cold Spring Harb Perspect Biol. 2018;10:a022327.

98. Bond AM, Bhalala OG, Kessler JA. The dynamic role of bone morphogenetic proteins in neural stem cell fate and maturation. Dev Neurobiol. 2012;72:1068-84.

99. Wang RN, Green J, Wang Z, Deng Y, Qiao M, Peabody M, et al. Bone morphogenetic protein (BMP) signaling in development and human diseases. Genes Dis. 2014;1:87-105.

100. Hamilton SP, Woo JM, Carlson EJ, Ghanem N, Ekker M, Rubenstein JLR. Analysis of four DLX homeobox genes in autistic probands. BMC Genet. 2005;6:52.

101. Liu X, Novosedlik N, Wang A, Hudson ML, Cohen IL, Chudley AE, et al. The DLX1and DLX2 genes and susceptibility to autism spectrum disorders. Eur J Hum Genet. 2009;17:228-35.

102. Rubenstein JLR, Merzenich MM. Model of autism: increased ratio of excitation/ inhibition in key neural systems. Genes Brain Behav. 2003;2:255-67.
103. Choy SW, Cheng SH. Hedgehog signaling. Vitam Horm. 2012;88:1-23.

104. Álvarez-Buylla A, Ihrie RA. Sonic hedgehog signaling in the postnatal brain. Semin Cell Dev Biol. 2014;33:105-11.

105. Kirschen GW, Xiong Q. Primary cilia as a novel horizon between neuron and environment. Neural Regen Res. 2017;12:1225-30.

106. Seppala M, Fraser GJ, Birjandi AA, Xavier GM, Cobourne MT. Sonic hedgehog signaling and development of the dentition. J Dev Biol. 2017;5:6.

107. Ghanizadeh A. Malondialdehyde, BCl-2, superoxide dismutase and glutathione peroxidase may mediate the association of sonic hedgehog protein and oxidative stress in autism. Neurochem Res. 2012:37:899-901.

108. Al-Ayadhi LY. Relationship between sonic hedgehog protein, brain-derived neurotrophic factor and oxidative stress in autism spectrum disorders. Neurochem Res. 2012;37:394-400.

109. Tora D, Gomez AM, Michaud JF, Yam PT, Charron F, Scheiffele P. Cellular functions of the autism risk factor PTCHD1 in mice. J Neurosci. 2017;37:11993-2005.

110. Ung DC, lacono G, Méziane $H$, Blanchard E, Papon MA, Selten $M$, et al. Ptchd1 deficiency induces excitatory synaptic and cognitive dysfunctions in mouse. Mol Psychiatry. 2017.

111. Blassberg R, Macrae JI, Briscoe J, Jacob J. Reduced cholesterol levels impair Smoothened activation in Smith-Lemli-Opitz syndrome. Hum Mol Genet. 2016;25:693-705.

112. Brune CW, Korvatska E, Allen-Brady K, Cook EH, Dawson G, Devlin B, et al. Heterogeneous association between engrailed-2 and autism in the CPEA network. Am J Med Genet B Neuropsychiatr Genet. 2008;147B:187-93.

113. Sen B, Singh AS, Sinha S, Chatterjee A, Ahmed S, Ghosh S, et al. Familybased studies indicate association of Engrailed 2 gene with autism in an Indian population. Genes Brain Behav. 2010;9:248-55.

114. Wang L, Jia M, Yue W, Tang F, Qu M, Ruan Y, et al. Association of the ENGRAlLED 2 (EN2) gene with autism in Chinese Han population. Am J Med Genet B Neuropsychiatr Genet. 2008;147B:434-8.

115. Yang $\mathrm{P}$, Lung FW, Jong YJ, Hsieh HY, Liang CL, Juo SH. Association of the homeobox transcription factor gene ENGRAILED 2 with autistic disorder in Chinese children. Neuropsychobiology. 2008;57:3-8.

116. Yang P, Shu B-C, Hallmayer JF, Lung FW. Intronic single nucleotide polymorphisms of engrailed homeobox 2 modulate the disease vulnerability of autism in a Han Chinese population. Neuropsychobiology. 2010:62:104-15.

117. Choi J, Ababon MR, Soliman M, Lin Y, Brzustowicz LM, Matteson PG, et al. Autism associated gene, engrailed2, and flanking gene levels are altered in post-mortem cerebellum. PLoS One. 2014;9:e87208.

118. Gharani N, Benayed R, Mancuso V, Brzustowicz LM, Millonig JH. Association of the homeobox transcription factor, ENGRAILED 2, 3, with autism spectrum disorder. Mol Psychiatry. 2004;9:474-84.

119. Wechsler-Reya RJ, Scott MP. Control of neuronal precursor proliferation in the cerebellum by sonic hedgehog. Neuron. 1999;22:103-14.

120. Simon HH, Scholz C, O'Leary DDM. Engrailed genes control developmental fate of serotonergic and noradrenergic neurons in midand hindbrain in a gene dose-dependent manner. Mol Cell Neurosci. 2005;28:96-105

121. Turner CA, Eren-Kocak E, Inui EG, Watson SJ, Akil H. Dysregulated fibroblast growth factor (FGF) signaling in neurological and psychiatric disorders. Semin Cell Dev Biol. 2016:53:136-43.

122. Ornitz DM, Itoh N. The fibroblast growth factor signaling pathway. Wiley Interdiscip Rev Dev Biol. 2015:4:215-66.

123. Amaral DG, Schumann CM, Nordahl CW. Neuroanatomy of autism. Trends Neurosci. 2008:31:137-45.

124. Terauchi A, Johnson-Venkatesh EM, Toth AB, Javed D, Sutton MA, Umemori $H$. Distinct FGFs promote differentiation of excitatory and inhibitory synapses. Nature. 2010;465:783-7.

125. Huang JY, Lu HC. mGluR5 tunes NGF/TrkA signaling to orient spiny stellate neuron dendrites toward thalamocortical axons during whisker-barrel map formation. Cereb Cortex. 2017:1-16.

126. Niederreither K, Dollé P. Retinoic acid in development: towards an integrated view. Nat Rev Genet. 2008;9:541-53.

127. Duester G. Retinoic acid synthesis and signaling during early organogenesis. Cell. 2008;134:921-31.

128. Rhinn M, Dollé $\mathrm{P}$. Retinoic acid signalling during development. Development. 2012;139:843-58.

129. Das BC, Thapa P, Karki R, Das S, Mahapatra S, Liu TC, et al. Retinoic acid signaling pathways in development and diseases. Bioorg Med Chem. 2014;22:673-83. 
130. Zieger E, Schubert M. New insights into the roles of retinoic acid signaling in nervous system development and the establishment of neurotransmitter systems. Int Rev Cell Mol Biol. 2017;330:1-84.

131. Siegenthaler JA, Ashique AM, Zarbalis K, Patterson KP, Hecht JH, Kane MA, et al. Retinoic acid from the meninges regulates cortical neuron generation. Cell. 2009;139:597-609.

132. Lai X, Wu X, Hou N, Liu S, Li Q, Yang T, et al. Vitamin a deficiency induces autistic-like behaviors in rats by regulating the RARB-CD38-oxytocin axis in the hypothalamus. Mol Nutr Food Res. 2018;62:1700754.

133. Nguyen A, Rauch TA, Pfeifer GP, Hu WW. Global methylation profiling of lymphoblastoid cell lines reveals epigenetic contributions to autism spectrum disorders and a novel autism candidate gene, RORA, whose protein product is reduced in autistic brain. FASEB J. 2010;24:3036-51.

134. Sayad A, Noroozi R, Omrani MD, Taheri M, Ghafouri-Fard S. Retinoic acidrelated orphan receptor alpha (RORA) variants are associated with autism spectrum disorder. Metab Brain Dis. 2017;32:1595-601.

135. Moreno-Ramos OA, Olivares AM, Haider NB, de Autismo LC, Lattig MC Whole-exome sequencing in a South American cohort links ALDH1A3, FOXN1 and retinoic acid regulation pathways to autism spectrum disorders. PLoS One. 2015;10:e0135927.

136. Pavăl D, Rad F, Rusu R, Niculae AS, Colosi HA, Dobrescu I, et al. Low retinal dehydrogenase 1 (RALDH1) level in prepubertal boys with autism spectrum disorder: a possible link to dopamine dysfunction. Clin Psychopharmacol Neurosci. 2017;15:229-36

137. Fregeau B, Kim BJ, Hernández-García A, Jordan VK, Cho MT, Schnur RE, et al. De novo mutations of RERE cause a genetic syndrome with features that overlap those associated with proximal 1 p36 deletions. Am J Hum Genet. 2016;98:963-70.

138. Sarachana T, Hu WW. Genome-wide identification of transcriptional targets of RORA reveals direct regulation of multiple genes associated with autism spectrum disorder. Mol Autism. 2013;4:14.

139. Xu X, Li C, Gao X, Xia K, Guo H, Li Y, et al. Excessive UBE3A dosage impairs retinoic acid signaling and synaptic plasticity in autism spectrum disorders. Cell Res. 2018;28:48-68.

140. Riebold M, Mankuta D, Lerer E, Israel S, Zhong S, Nemanov L, et al. All-trans retinoic acid upregulates reduced CD38 transcription in lymphoblastoid cell lines from autism spectrum disorder. Mol Med. 2011;17:799-806.

141. Kim S, Kim T, Lee HR, Jang EH, Ryu HH, Kang $M$, et al. Impaired learning and memory in CD38 null mutant mice. Mol Brain. 2016;9:16.

142. Avraham Y, Berry EM, Donskoy M, Ahmad WA, Vorobiev L, Albeck A, et al. Beta-carotene as a novel therapy for the treatment of "autistic like behavior" in animal models of autism. Behav Brain Res. 2017.

143. Wang Y, Billon C, Walker JK, Burris TP. Therapeutic effect of a synthetic RORa/Y agonist in an animal model of autism. ACS Chem Neurosci. 2016;7:143-8.

144. Tsarovina K, Reiff T, Stubbusch J, Kurek D, Grosveld FG, Parlato R, et al. The Gata3 transcription factor is required for the survival of embryonic and adult sympathetic neurons. J Neurosci. 2010;30:10833-43.

145. Notani D, Gottimukkala KP, Jayani RS, Limaye AS, Damle MV, Mehta S, et al. Global regulator SATB1 recruits beta-catenin and regulates $T(H) 2$ differentiation in Wnt-dependent manner. PLoS Biol. 2010;8:e1000296.

146. Kim HW, Hong R, Choi EY, Yu K, Kim N, Hyeon JY, et al. A probiotic mixture regulates $T$ cell balance and reduces atopic dermatitis symptoms in mice. Front Microbiol. 2018;9:2414.

147. Forsman CL, Ng BC, Heinze RK, Kuo C, Sergi C, Gopalakrishnan R, et al. BMPbinding protein twisted gastrulation is required in mammary gland epithelium for normal ductal elongation and myoepithelial compartmentalization. Dev Biol. 2013;373:95-106.

148. Rout UK, Clausen P. Common increase of GATA-3 level in PC-12 cells by three teratogens causing autism spectrum disorders. Neurosci Res. 2009:64:162-9.

149. Chess S. Autism in children with congenital rubella. J Autism Child Schizophr. 1971;1:33-47.

150. Richetto J, Massart R, Weber-Stadlbauer U, Szyf M, Riva MA, Meyer U. Genome-wide DNA methylation changes in a mouse model of infectionmediated neurodevelopmental disorders. Biol Psychiatry. 2017;81:265-76.

151. Moore SJ, Turnpenny P, Quinn A, Glover S, Lloyd DJ, Montgomery T, et al. A clinical study of 57 children with fetal anticonvulsant syndromes. J Med Genet. 2000;37:489-97

152. Qin L, Dai X. Effect of sulindac on improving autistic behaviors in rats. Nan Fang Yi Ke Da Xue Xue Bao. 2015;35:1162-5.
153. Song L, Li ZY, Liu WP, Zhao MR. Crosstalk between Wnt/ $\beta$-catenin and hedgehog/Gli signaling pathways in colon cancer and implications for therapy. Cancer Biol Ther. 2015;16:1-7.

154. Wang B, Li Y. Evidence for the direct involvement of $\beta \operatorname{TrCP}$ in Gli3 protein processing. Proc Natl Acad Sci U S A. 2006;103:33-8.

155. Tempé D, Casas M, Karaz S, Blanchet-Tournier M-F, Concordet JP. Multisite protein kinase $A$ and glycogen synthase kinase 3 beta phosphorylation leads to Gli3 ubiquitination by SCFbetaTrCP. Mol Cell Biol. 2006;26:4316-26.

156. Hart M, Concordet JP, Lassot I, Albert I, del los Santos $\mathrm{R}_{t}$ Durand $\mathrm{H}_{\text {, et al. The }}$ F-box protein beta-TrCP associates with phosphorylated beta-catenin and regulates its activity in the cell. Curr Biol. 1999:9:207-10.

157. Varnat F, Siegl-Cachedenier I, Malerba M, Gervaz P, Ruiz i Altaba A. Loss of WNTTCF addiction and enhancement of HH-GLI1 signalling define the metastatic transition of human colon carcinomas. EMBO Mol Med. 2010;2:440-57.

158. Meng X, Poon R, Zhang X, Cheah A, Ding Q, Hui CC, et al. Suppressor of fused negatively regulates beta-catenin signaling. J Biol Chem. 2001;276:40113-9.

159. Dunaeva M, Michelson $P$, Kogerman $P$, Toftgard R. Characterization of the physical interaction of Gli proteins with SUFU proteins. J Biol Chem 2003;278:5116-22

160. Tukachinsky H, Lopez LV, Salic A. A mechanism for vertebrate hedgehog signaling: recruitment to cilia and dissociation of SuFu-Gli protein complexes. J Cell Biol. 2010;191:415-28.

161. Rychahou PG, Kang J, Gulhati P, Doan HQ, Chen LA, Xiao SY, et al. Akt2 overexpression plays a critical role in the establishment of colorectal cancer metastasis. Proc Natl Acad Sci U S A. 2008;105:20315-20.

162. Arimura S, Matsunaga A, Kitamura T, Aoki K, Aoki M, Taketo MM. Reduced level of smoothened suppresses intestinal tumorigenesis by downregulation of Wnt signaling. Gastroenterology. 2009;137:629-38.

163. Ulloa F, Itasaki N, Briscoe J. Inhibitory Gli3 activity negatively regulates Wnt/ beta-catenin signaling. Curr Biol. 2007;17:545-50.

164. Li X, Deng W, Lobo-Ruppert SM, Ruppert JM. Gli1 acts through Snail and E-cadherin to promote nuclear signaling by beta-catenin. Oncogene. 2007;26:4489-98.

165. Javelaud D, Pierrat MJ, Mauviel A. Crosstalk between TGF- $\beta$ and hedgehog signaling in cancer. FEBS Lett. 2012;586:2016-25.

166. Chung Y, Fu E. Crosstalk between Shh and TGF- $\beta$ signaling in cyclosporine-enhanced cell proliferation in human gingival fibroblasts. PLoS One. 2013;8:e70128.

167. Glinka Y, Stoilova S, Mohammed N, Prud'homme GJ. Neuropilin-1 exerts coreceptor function for TGF-beta-1 on the membrane of cancer cells and enhances responses to both latent and active TGF-beta. Carcinogenesis. 2011:32:613-21.

168. Hillman RT, Feng BY, Ni J, Woo WM, Milenkovic L, Hayden Gephart MG, et al. Neuropilins are positive regulators of hedgehog signal transduction. Genes Dev. 2011;25:2333-46.

169. Hochman E, Castiel A, Jacob-Hirsch J, Amariglio N, Izraeli S. Molecular pathways regulating pro-migratory effects of hedgehog signaling. J Biol Chem. 2006:281:33860-70.

170. Fan Q, He M, Sheng T, Zhang X, Sinha M, Luxon B, et al. Requirement of TGFbeta signaling for SMO-mediated carcinogenesis. J Biol Chem. 2010;285:36570-6

171. Pierrat MJ, Marsaud V, Mauviel A, Javelaud D. Expression of microphthalmiaassociated transcription factor (MITF), which is critical for melanoma progression, is inhibited by both transcription factor GLI2 and transforming growth factor- $\beta$. J Biol Chem. 2012;287:17996-8004.

172. Stulberg MJ, Lin A, Zhao H, Holley SA. Crosstalk between Fgf and Wnt signaling in the zebrafish tailbud. Dev Biol. 2012;369:298-307.

173. Wang $Y$, Song $L$, Zhou CJ. The canonical Wnt/ $\beta$-catenin signaling pathway regulates Fgf signaling for early facial development. Dev Biol. 2011;349:250-60.

174. Itasaki N, Hoppler S. Crosstalk between Wnt and bone morphogenic protein signaling: a turbulent relationship. Dev Dyn. 2010;239:16-33.

175. Song L, Li Y, Wang K, Wang YZ, Molotkov A, Gao L, et al. Lrp6-mediated canonical Wnt signaling is required for lip formation and fusion. Development. 2009;136:3161-71.

176. Zhou CJ, Wang YZ, Yamagami T, Zhao T, Song L, Wang K. Generation of Lrp6 conditional gene-targeting mouse line for modeling and dissecting multiple birth defects/congenital anomalies. Dev Dyn. 2010;239:318-26. 